\title{
The shear strength of bedding partings in shales of the Pilbara: the similarity of non-dilatational angles, mineralogy relationships, and nominal roughness
}

\author{
A Maldonado The University of Western Australia, Australia \\ PM Dight Australian Centre for Geomechanics, The University of Western Australia, Australia
}

\begin{abstract}
Laboratory direct shear test results for natural bedding and sawcut defects have been statistically analysed in shales and banded iron formation materials across BHP Western Australian Iron Ore deposits (BHP WAIO) to prove the hypothesis of similarity of shear strength of defects.

The following paper provides typical Hencher corrected friction angles based on statistical methods to group data sharing similar characteristics. This paper justifies the existence of similar populations of shear strength of defects based on rigorous statistical analysis of valid direct shear test samples collected from multiple projects of the Pilbara. Spatial distribution bias effects and normality tests have been checked. Surface 'geotechnical' weathering grades do not explain the reduction of the shear strength of defects in shales. The use of base of completed oxidation and spectral signatures have provided a better explanation for the variability observed on the shear strength of defects. Where weathered shale samples from the Brockman column have greater frictional strength than fresh samples, a paradoxical phenomenon that can be attributed to chemical alteration generating additional textural roughness.
\end{abstract}

Keywords: shear strength, shale, bedding partings

\section{Introduction}

Laboratory direct shear test results for natural bedding and sawcut defects have been statistically analysed in shales and banded iron formation (BIF) materials across BHP Western Australian Iron Ore deposits (BHP WAIO) to prove the hypothesis of similarity of shear strength of defects.

This paper provides typical Hencher corrected friction angles based on inferred statistical methods to group data sharing similar characteristics. The paper aims to firstly demonstrate that the knowledge of the shear strength of bedding planes from laboratory testing is sufficient to provide the engineer with reliable Hencher corrected friction angles for formations and stratigraphic units encountered across BHP WAIO and secondly, to justify the use of the precision index as a way to minimise laboratory testing.

The paper demonstrates that Hencher corrected friction angles within the dominant lithological units are consistent across the BHP WAIO, are similar in magnitude and with sufficient precision to be used as typical values for slope design with minimal error, using an interval of confidence of $95 \%$ about the sample mean.

\section{Geology context}

The iron ore deposits of Western Australia are located in the Pilbara region of the state. Mining operations extract the iron-enriched deposits through numerous open pit excavations within the Hamersley province, which covers an area of $80,000 \mathrm{~km}^{2}$ and contains late Archaean-Lower Proterozoic age sediments. The province contains three constituent groups: the Fortescue, Hamersley and the Turee Creek Groups.

The BIF of the Hamersley Group is characteristically fine-grained and layered sedimentary rocks comprising alternating cherts, iron oxide, shales and carbonates. BIFs were formed by the rhythmic deposition of 
dominantly deep-water chemical sediments, which then underwent some form of mineralisation or enrichment to create the current orebodies.

The sedimentary rocks within the Hamersley Group are further sub-divided into stratigraphical formations including, from youngest to oldest and as follows:

- Brockman iron formation.

- Mt McRae formation.

- Mt Sylvia formation.

- Wittenoom formation.

- Marra Mamba iron formation.

The BHP exploration geology team commonly segregates the geology of the Pilbara in terms of Brockman and Marra Mamba deposits, based on the orebody mineralogy type. The upper stratigraphical portion of the Hamersley Group comprises the Brockman deposits (Joffre, Brockman, Mt McRae, and Mt Sylvia units), which are characterised by dominant hematite content, whilst the bottom of the Hamersley Group comprises the Marra Mamba deposits (Wittenoom formation and Marra Mamba iron formation), are characterised by dominant goethite content (Kepert, 2001). From the practical point of view, this major subdivision of Brockman and Marra Mamba deposits is applied to segregate the direct shear test data for hypothesis testing.

\section{$3 \quad$ Mineralogy study and the base of complete oxidation}

A recent mineralogy study in BHP was proposed by the first author to assess the concept of dividing the stratigraphical column of the Hamersley Group in the two major units and to explore the effect of weathering and/or alteration in the mineralogy changes within each stratigraphical column. The use of the base of complete oxidation (BOCO) was implemented to define two subsets of data for each stratigraphical column: weathered (above BOCO) and unweathered (below BOCO). BOCO is defined as the horizon of $100 \%$ oxidised material. Typically, rocks from below BOCO will contain traces of sulphides, magnetite and carbonates, whilst rocks above BOCO will contain iron oxides but without sulphides traces.

The results of this study reveal the following:

- There are chemical differences between materials within each stratigraphical column.

- There are consistent chemical differences in materials from above to below BOCO.

- Quartz is a dominant mineral within all interpreted unweathered stratigraphical units.

- The reduction of quartz and increase of iron oxides is the common phenomenon within weathered Brockman and Marra Mamba formations, with minor effect on McRae formation. The uniqueness of the McRae formation can be related to the lack of mineralisation within this strat unit.

- It appears rational to split the stratigraphy of the Hamersley Group into Brockman and Marra Mamba columns based on mineralogy distinctions: the Brockman column has a higher hematite content, whilst the Marra Mamba column has a higher goethite content.

\section{$4 \quad$ Direct shear testwork}

An external laboratory service provider (E-Precision) conducted direct shear tests (DST) of samples collected during diamond drilling activities across several BHP Pilbara iron ore deposits. The preference was for testing natural bedding partings with some allowance for testing of artificial sawcut samples in the absence of natural partings. 
The main objective of testing was the determination of the dilation corrected basic friction angle of defects per rock type (i.e. Shale and BIF lithologies in the Pilbara environment), which is one of the main inputs for slope stability analysis. The sampling was biased to shale defects, which are more critical for slope stability in open pits, whilst lesser sampling and testing occurred in the competent iron-rich materials (BIF).

It is important to mention that Hencher, S \& Richards, LR (2015) prefers the testing of natural defect surfaces as a way to estimate the basic friction angle, whilst Hoek (2014) suggests that testing of artificial saw cuts are similarly reliable. In this study, the results of direct shear testing on both natural and artificial saw cuts are statistically compared to validate the hypothesis of any difference or similarity of shear strength.

Hencher (2012) describes that the determination of the basic friction angle through the analysis of laboratory direct shear testing data is not straightforward since the results of laboratory samples are affected by the contribution of minor asperities (over short profile lengths of $100 \mathrm{~mm}$ ) that add a dilation component to the basic friction angle.

Hencher (2012) recommends the application of a dilation correction to the stresses directly derived from laboratory test results in order to subtract the effect of the small-scale geometry and enable a better estimation of the basic friction angle (i.e. without dilation). The principle used for dilation correction is based on the Patton equation:

$$
\tau=\sigma \tan \left(\phi_{b}+i\right)
$$

where:

$$
\begin{aligned}
\tau & =\text { peak shear strength. } \\
\sigma & =\text { normal stress. } \\
\phi_{b} & =\text { basic friction angle. } \\
1 & =\text { laboratory scale dilation angle. }
\end{aligned}
$$

According to this concept, during shearing, rough surfaces will cause progressive overriding of asperities throughout the test, and then increase the shear strength to a peak value. Thus, the basic friction angle is assumed approximately constant whilst the dilation friction angle varies along the test progression.

The dilation component is instantaneously measured during testing by applying the relation: dilation angle $=$ $\mathrm{i}=$ arctangent (vertical displacement/horizontal displacement) then the dilation correction is applied to the stress data using the below relationships:

$$
\begin{aligned}
\tau_{\text {corrected }} & =(\tau \cos i-\sigma \sin i) \cos I \\
\sigma_{\text {corrected }} & =(\sigma \cos i+\tau \sin i) \cos I
\end{aligned}
$$

\section{$5 \quad$ Laboratory test result validity}

The BHP geotechnical team further validated the results from the DST. Samples with irregular shapes (in plan view) or presenting persistent contraction were considered invalid. Valid test certificates were visually checked to verify that the selected peak shear stresses are at the yielding point of the elastic region for each stage. Laboratory certificates included the dilation corrected friction angle and the apparent cohesion as parameters calculated from linear regression fitting of the dilation corrected peak shear stresses.

Several of the recorded shear stress-shear displacement curves are quite irregular, containing steps and flat sections. This is caused by the low resolution of the transducers previously used in the laboratory. This resolution was improved from 0.01 to $0.001 \mathrm{kN}$ from 2015 onwards. In 2014, BHP personnel realised that the direct shear testing practices were below an acceptable standard (these samples affected some projects, becoming a legacy). Issues related to inadequate sample preparation, area correction, Hencher dilation correction and roughness profile records. For these reasons, several samples have been deemed invalid for this analysis. 
Occasionally, the linear regression fitting causes some negative cohesion values, which are a product of uncontrolled contraction of the test during the initial stage. Whilst this negative cohesion does not detract from the value of the test, the laboratory has reported the cohesion as being zero, without performing re-calculation of the friction angle for post-contraction stages. Therefore, the first author was required to re-calculate the dilation corrected peak friction angle by disregarding the stage of contraction and conducting the linear regression with a zero intercept (this is a secant friction angle).

\section{$6 \quad$ Statistical methods}

For simplicity, the shear strength of defects has been calculated using a fixed normal stress of $350 \mathrm{kPa}$, in order to combine the effects of both friction and apparent cohesion in just one variable. Before commencing the statistical analysis, the following conditions were checked:

- Individual samples are well distributed across multiple projects of the Pilbara (spatial distribution).

- A minimum number of five samples per stratigraphy were considered for hypothesis testing (sample size).

- All samples when grouped by lithology are approximately normally distributed (normality testing).

The analysis of statistical data was conducted using the MINITAB software (2019). The significant results of the data analysis are presented within the paper.

In order to prove the existence of similar populations, statistical hypothesis testing methods were applied to compare the similarity of the mean and variance of either two or more combined samples. These were the F-test and T-test, and the analysis of variance test (ANOVA) with Tukey's procedure, described below:

- F-test and T-test: when comparing two samples, the Student T-test method was applied to verify the similarity of mean values, whilst the Fisher F-test to check the similarity of variances.

- Analysis of variance test (ANOVA) in conjunction with Tukey's procedure: when comparing more than two samples; ANOVA was employed to verify the similarity of variances in conjunction to Tukey's 'pairwise' procedure to check the similarity of the mean values, as presented by Maldonado \& Haile (2015).

The application of the hypothesis testing methods required a minimum sample size of five elements for each group to ensure fair comparisons (Levine et al. 2013). As varying sample sizes limit the use of simple techniques, the application of ANOVA becomes a more robust method when aided by the Tukey's procedure that transfers the effects of different sample sizes into 'pairwise' comparisons.

The hypotheses are assessed on the basis of a $95 \%$ interval of confidence using the p-value of the statistic, where the $p$-value has to be greater than the level of significance for acceptance (i.e. $>5 \%$ ). More detail on these methods can be found in standard statistical books (Levine et al. 2013).

Note that the application of the above methods relies on three assumptions: the data is normally distributed, each sample has been taken at random from its respective populations, and the variance within each population must be similar to all populations (McKillup \& Dyar 2010).

\section{$7 \quad$ Analysis on spatial variability}

The spatial distribution of samples is presented in Figure 1 for shale across the BHP project areas. Visual examination suggests that sample collection is sufficiently distributed across the Pilbara.

A rigorous analysis of BIF samples by means of formation and stratigraphic unit distribution has not been included in this section, as BIFs are deemed low risk within open cut pit slope design as it is the shale bands within the BIF units that control the slope stability, being the weaker material. 


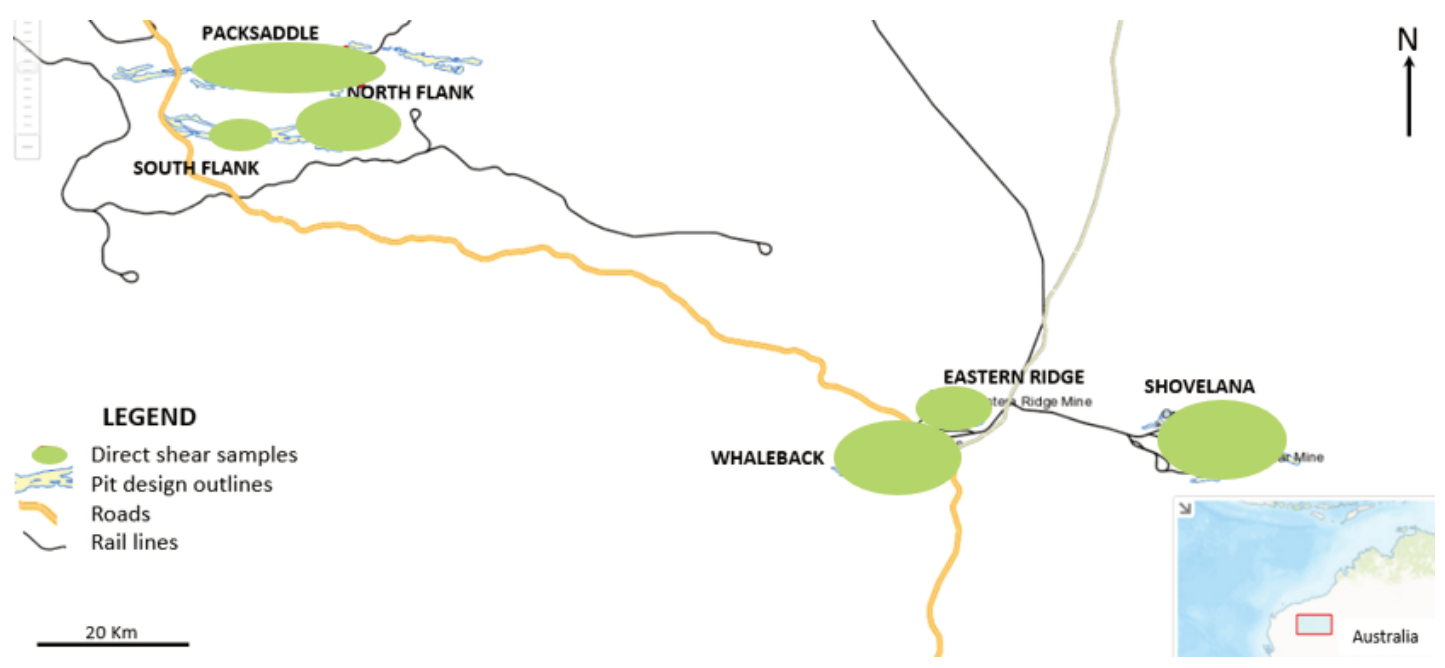

Figure 1 Spatial distribution of all shale samples across the BHPB WAIO

The shale sample population (without differentiation of weathering grade) is presented in Table 1 by stratigraphic unit and formation per BHP WAIO project area. The data was used to create the spatial distribution map in Figures 1 and 2. From Table 1, it is shown that for the most significant stratigraphic units - which are known to control the stability of slopes within open cut pits (i.e. W, D, R, MM and N) - a sufficient sample size for most project areas is available for testing.

There is some sampling bias towards the Whaleback (WH) project area as this is one of the deepest open cut pits (covering the Marra Mamba and Brockman formations) and has multiple pushbacks that have all been extensively drilled over the years. The other projects have limited sample size for some stratigraphic units due to their much shallower depth and limited development with less diamond drilling.

The subsequent testing is based on a 'comparison' of stratigraphic units that have a minimum sample size of five within each project area. An exception is applied at the South Flank (SF) and North Flank (NF) project areas, where the samples of MacLeod (MM), Nammuldi (MU) and Mt Newman (N) were combined due to limited data. This is justified by the fact that the NF and SF projects are part of same orebody boundary, with similar geology including stratigraphical units, weathering profile, structural setting and mineralisation, which provide geological support to the decision of combining the samples of both projects as presented in Table 1.

Table 1 Distribution of all shales samples by stratigraphic unit and by project

\begin{tabular}{|c|c|c|c|c|c|c|c|}
\hline \multirow[t]{2}{*}{ Formation } & \multirow[t]{2}{*}{ Stratigraphic unit } & \multicolumn{6}{|c|}{ Project area } \\
\hline & & $\begin{array}{l}\text { North } \\
\text { Flank }\end{array}$ & $\begin{array}{l}\text { South } \\
\text { Flank }\end{array}$ & Packsaddle & $\begin{array}{l}\text { Eastern } \\
\text { Ridge }\end{array}$ & Shovelana & Whaleback \\
\hline \multirow[t]{4}{*}{ Brockman } & Yandicoogina & & & & 4 & 8 & \\
\hline & Joffre & & & & 5 & 2 & \\
\hline & Whaleback & & & 12 & 1 & 3 & 18 \\
\hline & Dales & & & 8 & 8 & & 13 \\
\hline Mt McRae & Mt McRae & & & 4 & 8 & 8 & 38 \\
\hline Mt Sylvia & Mt Sylvia & & & & & & 10 \\
\hline Wittenoom & West Angela & & & & & & 15 \\
\hline \multirow{3}{*}{$\begin{array}{l}\text { Marra } \\
\text { Mamba }\end{array}$} & Mt Newman & 6 & 2 & & & & 5 \\
\hline & MacLeod & 7 & 4 & & & & 6 \\
\hline & Nammuldi & & 2 & & & & 3 \\
\hline
\end{tabular}




\section{$8 \quad$ Normality testing}

Before commencing the statistical hypothesis, testing it is important to check the 'normality' of sample distribution, for which the Kolmogorov-Smirnov (KS) test is used. The results of the KS test for normality of shale samples is presented in Figure 2. Note that all samples are lumped together as a single population and the $p$-value of the test is $\sim 9 \%$, therefore the single population pass the normality test, i.e. $p$-value test of normality is greater than $5 \%$. Applying the KS test to BIF also resulted in a normal population.

It is not considered practical to test the normality of further subdivisions of the dataset, i.e. sub-groups based on permutations of weathering grades and stratigraphies, as the test of normality requires large sample sizes.

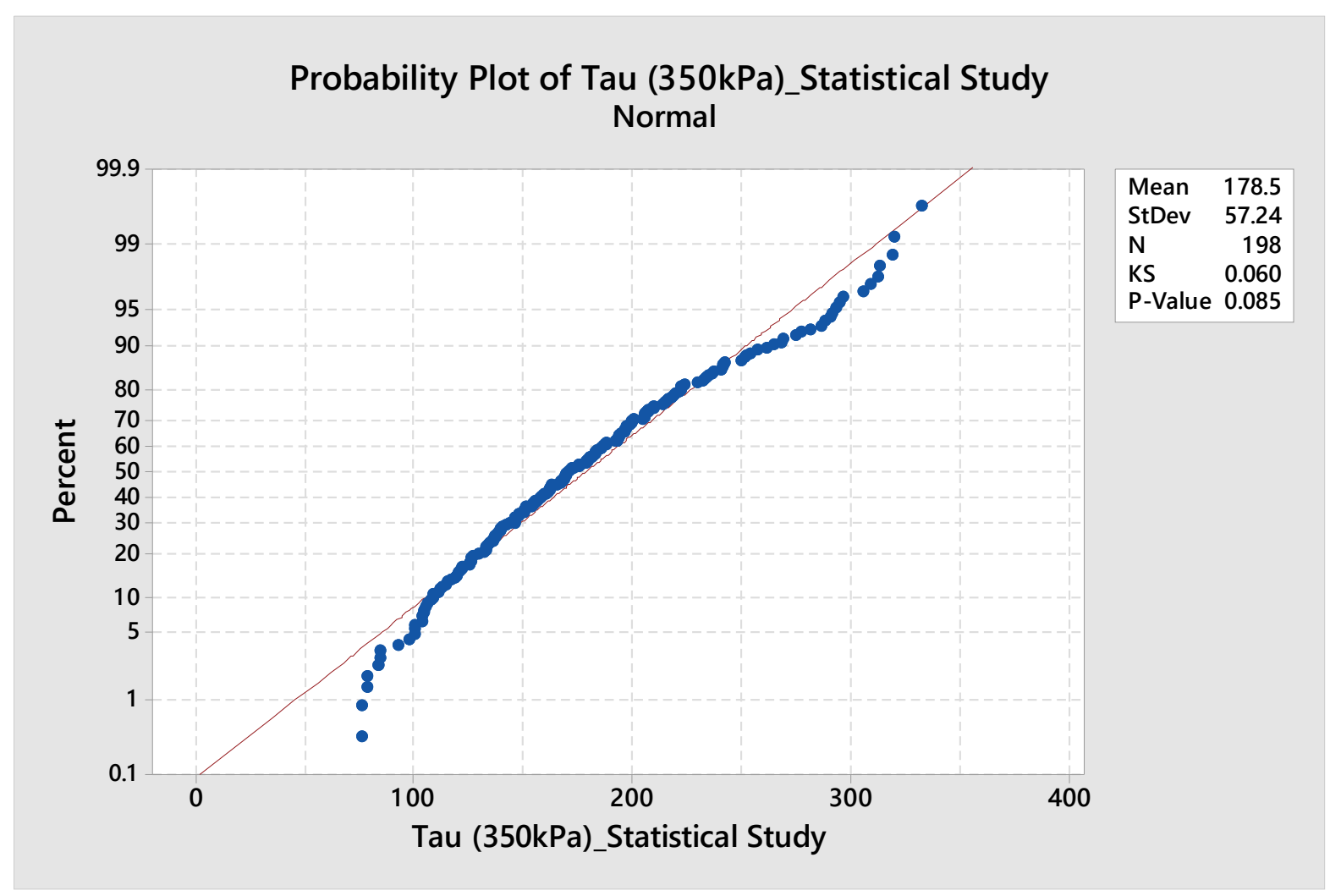

Figure 2 Screenshots from MINITAB for the test of normality for all of shales samples

\section{$9 \quad$ Statistical analysis results}

Table 2 presents the results of the hypothesis testing conducted on the sample populations. Stratigraphies across project areas were tested along with stratigraphies within project areas, to test the similarity between populations and the robustness of the data. 


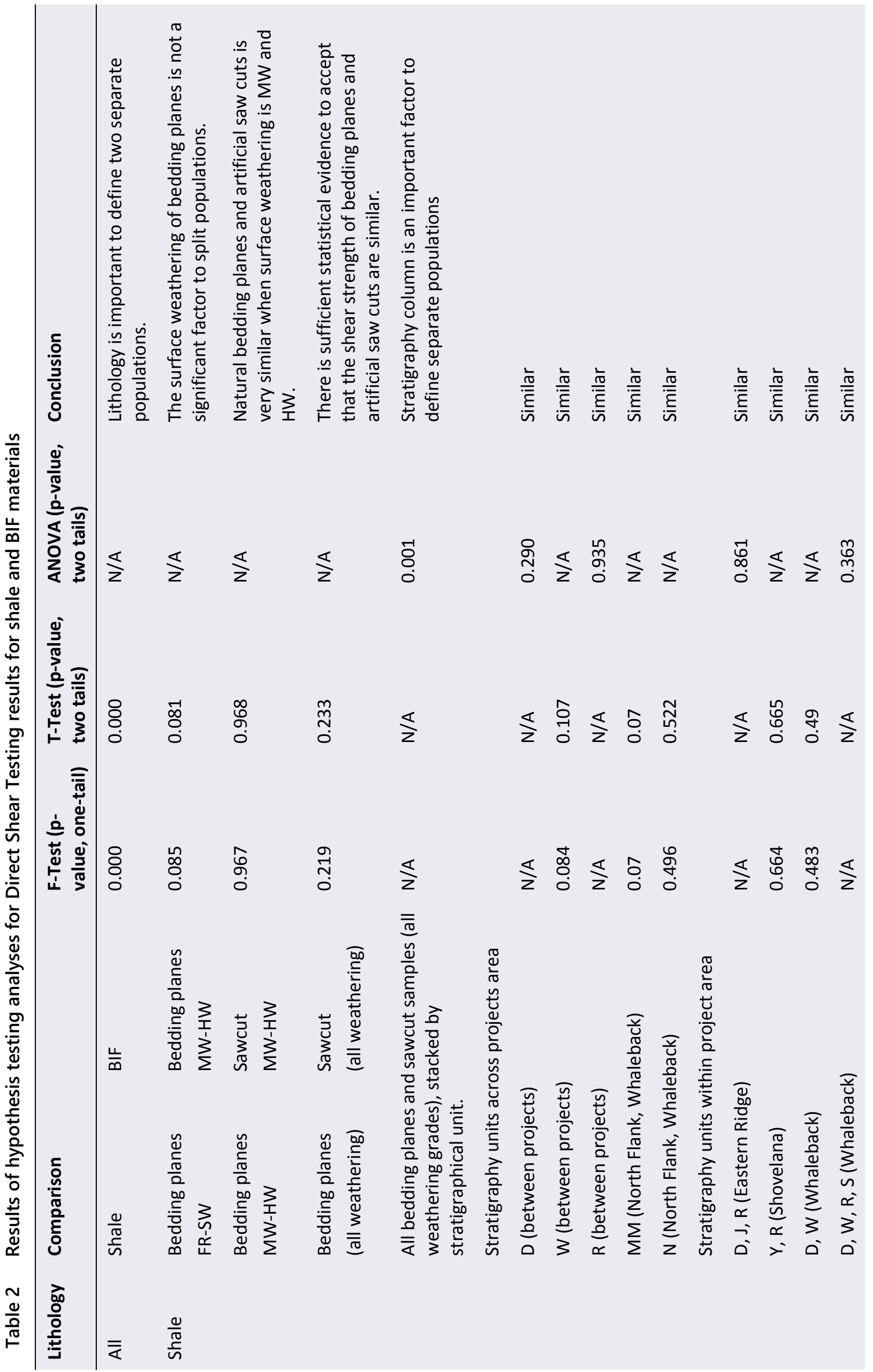




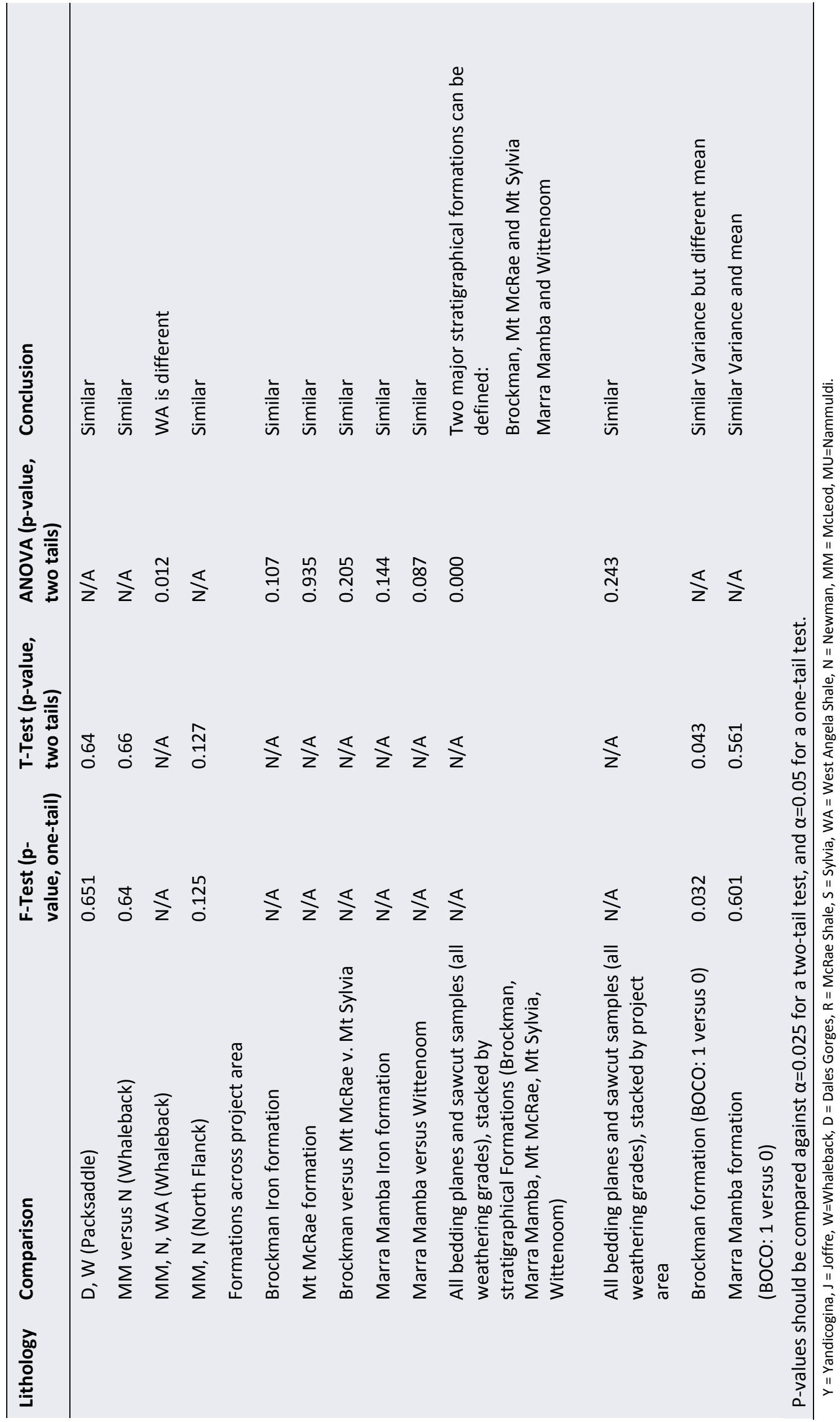




\section{Discussion on the statistical similarity}

Hypothesis testing proves that the distinction between shale and BIF lithologies is an important factor to define the shear strength of defects. There is a similarity between the shear strength of natural bedding planes and artificial saw cuts, in which weathering grade has no influence, i.e. fresh and slightly weathered surfaces have similar strength to moderate and highly weathered surfaces.

The lack of influence of the weathering grades on the shear strength of defects may be explained by the weathering grades being subjectively assigned by loggers during sample collection, based on International Society for Rock Mechanics (1978). In the opinion of the authors, the weathering grades are not accurately assigned to shale materials mainly due to the practical difficulty of distinguishing between weathering induced surface staining and the typical variability of shale colours (e.g. black, white, brown, red and yellow). Colour variety is mostly related to chemical differences of shale composition.

In general, most of the shales in the Pilbara are located above the zone of surface oxidation, thus they will generally present weathered conditions rather than fresh. During slope design, direct shear test samples are normally assessed based on their logged surface weathering grades, in two sub-groups: weathered (moderate to highly weathered conditions) and fresh (slightly weathered to fresh conditions). However, the subjectivity of this classification tends to smear and 'homogenise' the laboratory data results, for the reasons explained earlier.

The grouping of laboratory data based on the (BOCO appears to better explain the variability observed on the shear strength). Defects above BOCO tend to have more frictional resistance than below BOCO. This is relevant for shale samples in the Brockman column, but appears less relevant for shale samples within the Marra Mamba column and BIF samples within both Brockman and Marra Mamba columns.

In shale samples, there are notable differences in defect shear strength when considering the major stratigraphic divisions. Two major stratigraphical groups are clearly defined: the first is the combination of Brockman, Mt McRae and Mt Sylvia formations and the second is the combination of Marra Mamba and Wittenoom formations. These combinations can simply be referred to as the Brockman iron formation and the Marra Mamba iron formation, respectively. This major segregation is also reflected in the major subdivision of orebody type. This reveals that the statistical segregation of the direct shear test dataset has some relationship to the geological setting of the Pilbara, in particular with the ore formation.

In shale samples, there are no significant statistical differences to support regional variability related to project areas.

\section{$11 \quad$ Defining typical basic friction angles}

Table 3 presents the typical basic friction angles (dilation Hencher corrected) for shales and BIF materials. These values are presented for both the stratigraphical columns of Brockman and Marra Mamba formations and sub-groupings based on BOCO. These typical values can be selected by considering the mean as the most likely central value and the 25th percentile as the most likely lower case. Typical values can be applied to current projects and new projects based on the stratigraphic units and lithology for most of the cases.

The reliability of these typical values is quantified using two parametes: the Presicion Index and the Accuracy level. Gill \& Leite (2005a) and Gill, Corthesy and Leite (2005b) defined the Precision Index as the ratio between the upper and lower confidence intervals, whilst BHP (internal communication) defines the Accuracy as the standard error divided by the sample mean. The Accuracy is recommended to indicate to what level of design stage the typical values could be applied to (Accuracy of $10 \%$ for Detailed design, $20 \%$ for Provisional and 30\% for Conceptual).

For reference, the precision index is defined as the ratio between the upper and lower confidence intervals and the accuracy is defined as the standard error divided by the sample mean. The precision index values indicate that no more sampling is required to determine the basic friction angle into the Brockman or the Marra Mamba iron formations for shale materials. 
Table 3 Typical basic friction angles for shale

\begin{tabular}{|c|c|c|c|c|c|c|c|c|c|}
\hline $\begin{array}{l}\text { Relevant } \\
\text { stratigraphy }\end{array}$ & $\begin{array}{l}\text { Studied } \\
\text { projects }\end{array}$ & BOCO & $\begin{array}{l}\text { Median } \\
\left({ }^{\circ}\right)\end{array}$ & $\begin{array}{l}\text { Mean } \\
\left(\left(^{\circ}\right)\right.\end{array}$ & $\begin{array}{l}\text { Std. } \\
\operatorname{dev}\left({ }^{\circ}\right)\end{array}$ & $\begin{array}{l}\text { 25th } \\
\text { percentile }\end{array}$ & Accuracy & $\begin{array}{l}\text { Precision } \\
\text { index }\end{array}$ & $\begin{array}{l}\text { Design } \\
\text { level }\end{array}$ \\
\hline \multirow{2}{*}{$\begin{array}{l}\text { Brockman } \\
(Y, J, W, D, \\
R, S)\end{array}$} & $\begin{array}{l}\text { Packsaddle, } \\
\text { Eastern }\end{array}$ & Below & 22 & 23 & 7 & 17 & $4.9 \%$ & 1.22 & Detailed \\
\hline & $\begin{array}{l}\text { Ridge, } \\
\text { Shovelanna } \\
\text { Whaleback }\end{array}$ & Above & 26 & 26 & 6 & 22 & $2.5 \%$ & 1.10 & Detailed \\
\hline \multirow{2}{*}{$\begin{array}{l}\text { Marra } \\
\text { Mamba } \\
\text { (WA, N, } \\
\text { MM, MU) }\end{array}$} & North Flank & & & & & & & & \\
\hline & $\begin{array}{l}\text { South Flank } \\
\text { Whaleback }\end{array}$ & All & 28 & 29 & 7 & 25 & $3.4 \%$ & 1.14 & Detailed \\
\hline
\end{tabular}

$\mathrm{Y}=$ Yandicogina, $\mathrm{J}=$ Joffre, $\mathrm{W}=$ Whaleback, $\mathrm{D}=$ Dales Gorges, $\mathrm{R}=\mathrm{McR}$ (ae Shale, $\mathrm{S}=$ Sylvia, $\mathrm{WA}=$ West Angela Shale, $\mathrm{N}=\mathrm{Newman}, \mathrm{MM}=\mathrm{McLeod}$, $\mathrm{MU}=$ Nammuldi.

The friction angle of Brockman shales is additionally divided by BOCO, which is based on distinct chemical compositions from fresh (below BOCO) to weathered (above BOCO). In fresh conditions, natural defects can approach the lower bound of $17^{\circ}$ (25th percentile) when surfaces are polished, whilst the average friction angle of $23^{\circ}$ is representative of planar smooth conditions (not polished). The recent geochemical analysis of shale composition supports that the oxidation process has altered the original mineralogy of shales by changing the proportions of ferric oxides, quartz and clayey mineral contains. This chemical transformation provides an explanation for the relative increase in the basic friction angle in weathered shales of the Brockman column as presented in Figure 3 and Table 3.

The majority of friction angle data for Marra Mamba shales are in weathered (above BOCO). The basic friction angles for defects can be represented by the mean value of $29^{\circ}$ and the lower bound value of $25^{\circ}$. These friction angles are applicable for the stratigraphic units presented in Figure 4 and Table 3.

\section{Nominal roughness}

The Hencher correction is applied to the peak stresses of DST in order to remove the effects of dilation caused by either the overriding of roughness (small-scale geometry component) or the work carried out by mobilisation of debris during progressive shearing (asperities failure). Either way, the dilation phenomenon adds a nominal roughness angle to the basic friction angle, which should be accounted for in the estimation of the peak friction angle at the laboratory scale.

The nominal roughness angle is empirically related to Joint Roughness Coefficient (JRC) and Joint Compressive Strength (JCS) and the normal stress as defined by Barton (1973, 1976), Barton \& Choubey (1977) and Barton (1995). Interestingly, the dilation angles determined from DST data used in this study are lower than the values derived by the equation of Barton (1973). For pragmatism, it is only possible to estimate the nominal roughness angle based on JRC alone, at the lab scale (profile with a length between 10 and $20 \mathrm{~cm}$ ). Table 4 presents the relationships between material type, dilation angle and JRC that are recommended to estimate the nominal roughness angle for design purposes. 
Table 4 Typical nominal roughness for shales

\begin{tabular}{|c|c|c|c|c|c|}
\hline Rock type & Relevant stratigraphy & Studied projects & BOCO & R-square & $\begin{array}{l}\text { Nominal roughness } \\
\text { angle }\left(d^{\circ}\right)\end{array}$ \\
\hline \multirow{3}{*}{ Shale } & Brockman & $\begin{array}{l}\text { Packsaddle, } \\
\text { Eastern Ridge, }\end{array}$ & Below & 0.7 & $d^{\circ}=0.4 J R C$ \\
\hline & $(Y, J, W, D, R, S)$ & $\begin{array}{l}\text { Shovelana, } \\
\text { Whaleback }\end{array}$ & Above & N/A & $d^{\circ}=0$ \\
\hline & $\begin{array}{l}\text { Marra Mamba } \\
\text { (WA, N, MM, MU) }\end{array}$ & $\begin{array}{l}\text { North Flank, } \\
\text { South Flank, } \\
\text { Whaleback }\end{array}$ & Either & N/A & $d^{\circ}=0$ \\
\hline
\end{tabular}

$\mathrm{Y}=$ Yandicogina, $\mathrm{J}=$ Joffre, $\mathrm{W}=$ Whaleback, $\mathrm{D}=$ Dales Gorges, $\mathrm{R}=\mathrm{McRae}$ Shale, $\mathrm{S}=$ Sylvia, $\mathrm{WA}=$ West Angela Shale, $\mathrm{N}=$ Newman, $\mathrm{MM}=\mathrm{McLeod}$, $\mathrm{MU}=$ Nammuldi.

\section{Application of typical Hencher corrected values in slope analysis and design}

For peak shear strength conditions, the frictional component is determined by adding the dilation corrected basic friction angle to the derived nominal roughness and any subsequent waviness component.

The slope stability analysis process is deterministic but includes a sensitivity analysis for two scenarios: the 'most likely case' (typically the mean friction angle) and the 'lower case' estimate (reflecting the lowest reasonable scenario). In this context, the values presented in Table 3 are used to define the mean and lower case scenarios for basic friction angle. Table 4 presents the relationships that are recommended to estimate nominal roughness for shale, from which the 'most likely' nominal roughness can be determined from JRC distribution (i.e. selecting the median of JRC for specific rock mass domain).

It must be noted that rock masses in the Pilbara present strong anisotropic strength, thus the impact of defect shear strength variability on the overall slope stability cannot be determined in isolation from the rock mass strength properties. This is considered during limit equilibrium analysis by including the Snowden linear anisotropic model (Mercer 2013) where the Hoek-Brown model is used to represent the isotropic rock mass strength, whilst the bedding shear strength is defined by a Mohr-Coulomb strength model (including waviness component) as ubiquitous directional strength. Analysis is conducted using Slide software (Slide limit equilibrium analysis from Rocscience Inc. 2018).

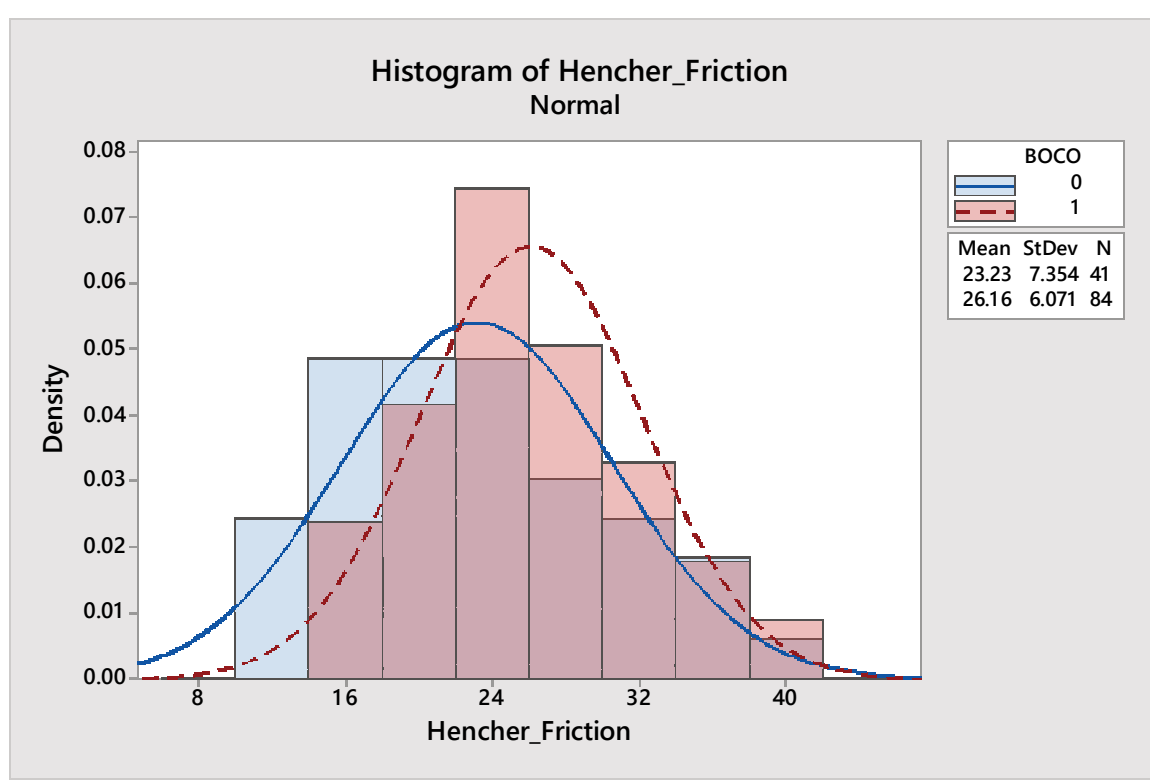

Figure 3 Histogram of Hencher corrected friction angle for shales in Brockman iron formation differentiated by above and below BOCO 


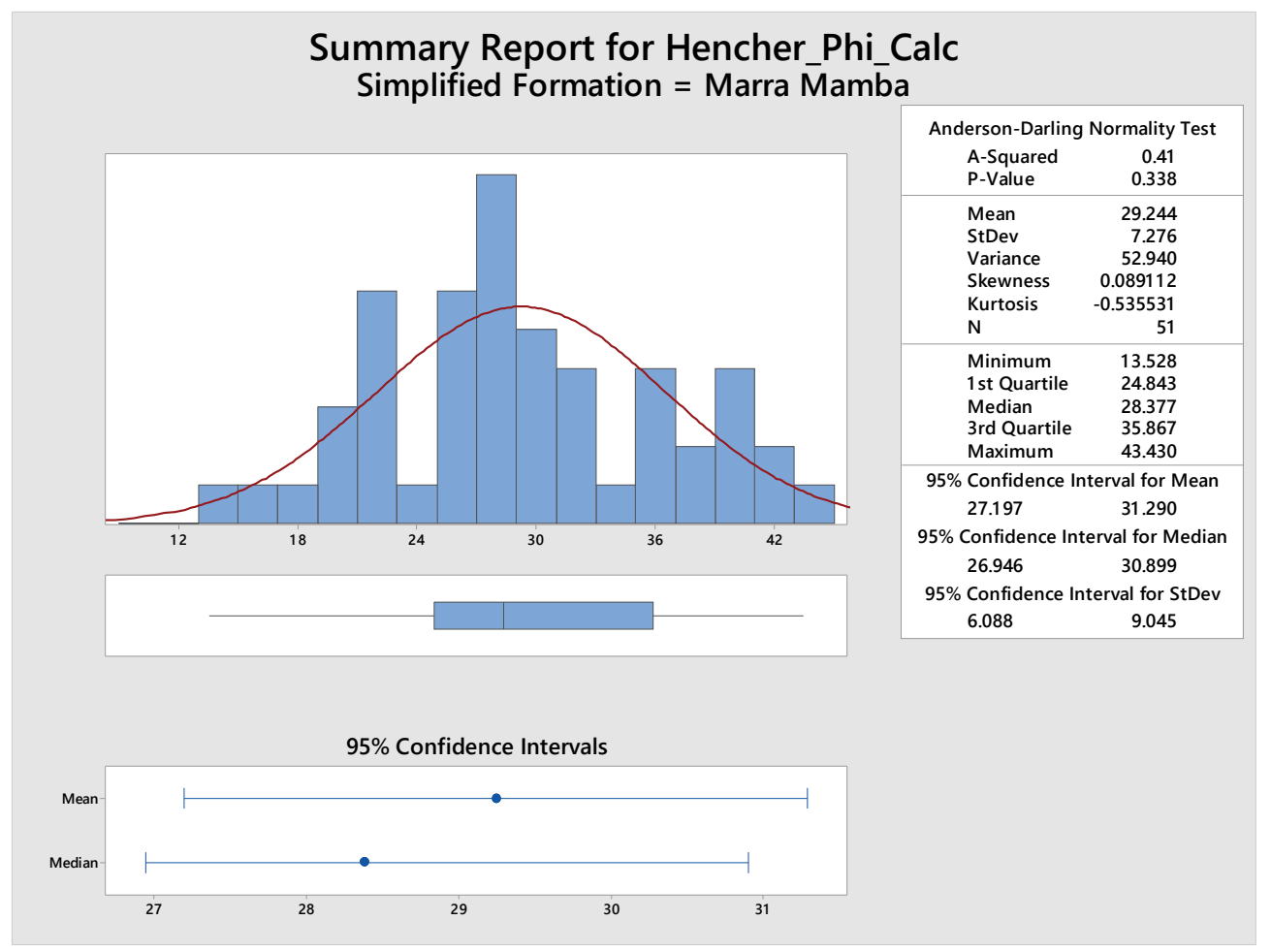

Figure 4 Histogram of Hencher corrected friction angle for shales in Marra Mamba iron formation

\section{Conclusion}

The current precision index of the Hencher's friction angle presented in Table 3 exceeds the precision needed for practical engineering design. The level of knowledge approached a research level (Gill et al. 2005).

The current state of accuracy on shear strength is sufficient to justify limited direct shear testing for the specific stratigraphy and lithology types listed in Table 3.

The use of Hencher friction angles for defining the bedding shear strength of defects increase the accuracy on modelling and promote a stream-line design process.

Table 4 presents the most accurate relationship to estimate nominal roughness for shale and BIF from logging data, from which the 'most likely' nominal roughness can be determined from JRC distribution (i.e. the median of JRC).

\section{Acknowledgement}

The authors thank the BHP geotechnical engineering team for supporting this work. In addition, the authors thank to Ted Brown as the external reviewer of the project in 2017. Similarly, the authors express their gratitude to Andy Haile and Ken Mercer for encouraging the PhD work since November 2015.

\section{References}

Barton, N 1973, 'Review of a new shear strength criterion for rock joints', Engineering Geology, vol. 7, pp. 287-332.

Barton, N 1976, 'The shear strength of rock and rock joints', International Journal of Rock Mechanics \& Mining Sciences, vol.13, pp. 255-279.

Barton, N 1995, 'The influence of joint properties in modelling jointed rock masses', Proceedings of the 8th International Society for Rock Mechanics Congress, International Society of Rock Mechanics, Salzburg, pp. 1023-1032.

Barton, N \& Bandis, SC 1990, 'Review of predictive capabilities of JRC-JCS model in engineering practice', in N Barton \& O Stephansson (eds), Proceedings of the International Symposium on Rock Joints, Balkema, Rotterdam, pp. 603-610.

Barton, N \& Choubey, V 1977, 'The shear strength of rock and rock joints in theory and practice', Journal of Rock Mechanics and Rock Engineering, vol. 10, pp. 1-54. 
Gill, DE, Ro, T \& Leite, MH 2005a, 'Determining the minimal number of specimens for laboratory testing of rock properties', Engineering Geology, vol. 78, vol. 1-2, pp. 29-51.

Gill, DE, Corthesy, R \& Leite, MH 2005b, 'A statistical approach for determining practical rock strength and deformability values from laboratory tests', Engineering Geology, vol. 78, issue 1-2, pp. 53-67.

Hencher, S 2012, Practical Engineering Geology, CRC Press, Boca Raton.

Hencher, S \& Richards, LR 2015, 'Assessing the shear strength of rock discontinuities at laboratory and field scales', Rock Mechanics \& Rock Engineering, vol. 48, issue 3, pp. 883-905.

Hoek, E 2004 Rock Engineering, Course notes, Canada, 313 p.

International Society for Rock Mechanics 1978, 'Suggested methods for the quantitative description of the discontinuities in rock masses', International Journal of Rock Mechanics and Mining Sciences \& Geomechanics Abstracts, vol. 15, issue 6, pp. 319-368.

Kepert, DA 2001, The mapped stratigraphy and structure of the mining Area C region, an eclectic synthesis of geological mapping by BHPBIO exploration 1994-2001, internal report.

Levine, DM, Stephan, DF \& Szabat, KA 2013, Statistics for Managers, Pearson Higher Ed USA, USA.

Mc Killup, S \& Dyar, MD 2010, Geostatistics Examined, An Introductory Guide for Earth Scientists, Cambridge University Press, Cambridge.

Maldonado, A \& Haile, A 2015, 'Application of ANOVA and Tuckey-Cramer, statistical analysis to determine similarity of rock mass strength properties across Banded Iron Formations of the Pilbara region in Western', in TR Stacey (ed.), Proceedings of the 2015 International Symposium on Slope Stability in Open Pit Mining and Civil Engineering, The Southern African Institute of Mining and Metallurgy, Johannesburg.

Mercer, K 2013, 'Linear Anisotropic Model History of development Part 1', Australian Centre for Geomechanics Newsletter, https://acg.uwa.edu.au/wp-content/uploads/2014/12/NL38_web_ref.pdf

Minitab Software 2019, https://www.minitab.com/en-us/

RocScience Inc. 2018, Slide2, computer software, https://www.rocscience.com/software/slide2 
The shear strength of bedding partings in shales of the Pilbara: the similarity of non-dilatational angles, mineralogy relationships, and nominal roughness

A Maldonado and PM Dight 